\title{
Review of: "COVID-19 and financial market response in China: Micro evidence and possible mechanisms"
}

\author{
Fengwen Chen ${ }^{1}$ \\ 1 Chongqing University
}

Potential competing interests: The author(s) declared that no potential competing interests exist.

This paper closely follows the hot spots, which studies the impact of COVID-19 on different industries in the financial market.

The advantages are as follows:

1. Clear structure and organization.

2. The research paradigm is relatively standardized and the conclusion is clear.

3. The arrangement of research levels is reasonable, from macro to micro.

Points that can be improved:

1. Literature review can be more focused according to the research focus.

2. The sample is Chinese Listed Enterprises with Chinese characteristics. Can the conclusion be extended to enterprises all over the world?

3. The research samples and methods are quite conventional. What is the most prominent difference between the paper and other similar research on COVID-19' s impacts? What are the innovations? 